\title{
Supplier Selection in the International Environment: A Comparative Case of a Turkish and an Australian Company ${ }^{1}$
}

\author{
Arzu Tektas ${ }^{1}$ and Aycan Aytekin ${ }^{2}$ \\ ${ }^{1}$ Department of International Trade, Bogazici University, Istanbul, Turkey \\ ${ }^{2}$ Import assistant specialist, Istanbul, Turkey
}

\begin{abstract}
International supplier selection, which is becoming a dominant strategy in an increasing number of sectors, is a multi-criterion decision problem. This study aims to contribute to this contemporary global issue initially by developing a multi-criteria hierarchical model for supplier selection utilizing the analytical hierarchy process (AHP). The AHP model aids decision making by quantifying the relative importance of each criterion and by ranking the suppliers. Secondly, The AHP model is augmented with a linear programming model which aims to maximize the buyer's total value of purchasing through optimal order splitting among suppliers. The augmented model will make it possible for the decision maker to observe the hierarchy of the supplier selection decision criteria, quantify the relative importance rate for each criterion, rank the suppliers, select the best supplier(s) and realize optimal order splitting among suppliers. Thirdly, the model is applied to a Turkish chemical company and an Australian one where the results point to some important differences in the two companies' decision criteria preferences and decision making habits. Although the findings cannot be generalized, this might pave the way for further analyses that will be conducted at country level. Comparative studies might aid not only in supplier selection but also in designing supply chains and supplier strategies.
\end{abstract}

Keywords: Supply chain, international supplier, analytic hierarchy process, linear programming, optimal allocation, order splitting, sensitivity analysis, Turkey, Australia

\footnotetext{
${ }^{1}$ This study is supported by Bogazici University Scientific Research Projects Fund (Project \#: 09N201D)
}

Copyright (C) 2011 Arzu Tektas and Aycan Aytekin. This is an open access article distributed under the Creative Commons Attribution License unported 3.0, which permits unrestricted use, distribution, and reproduction in any medium, provided that original work is properly cited. Contact author Arzu Tektas e-maill: tektas@boun.edu.tr 


\section{Introduction}

Effective supply chain management has become a valuable way of improving organizational performance and sustaining competitiveness in today's global business environment. Increases and varieties of customer demands, advances of recent technologies in communication and information systems, competition in global environment, decreases in governmental regulations and increases in environmental consciousness have forced companies to focus on the supply chain (Tracey and Tan, 2001). Consequently, these broadened the boundaries of supply chains and internationalized the supplier selection process. Although the literature contains abundant studies on domestic supplier selection, research on international supplier selection and the impacts of globalization on internationalization are more limited.

This study aims to contribute to the effective supply chain development of internationally sourcing companies by developing a multicriteria hierarchical model for supplier selection utilizing the analytical hierarchy process (AHP). It aids decision making by quantifying the relative importance of each criterion and by ranking and selecting the suppliers. The approach is implemented on a Turkish and an Australian company to note and interpret the similarities and differences in criteria prioritization of the companies. Finally, the AHP approach is augmented with a linear programming (LP) model that would maximize the total value of purchasing for the buyer through optimal order splitting among suppliers. Priority weights calculated by AHP will be used as input coefficients for LP. Using the augmented model, it will be possible for the decision maker to see the hierarchy of the supplier selection decision criteria, quantify the relative importance rate for each criterion, rank the suppliers, select the best supplier(s) and realize optimal order splitting among suppliers.

\section{Internationalization of Sourcing}

The official foundation of the European Community (EC) 1992 under the auspices of the Single European Act, the demise of Communism in the Eastern bloc countries and the pending ratification of the North American Free Trade Agreement contributed heavily to the globalization of the world economy (Min, 1994). The progressive lowering of trade barriers, the advancement of information and communication technologies, the development of transport systems and infrastructures have facilitated international trade and increased the level of competition worldwide (Nassimbeni, 2003). Intensifying degrees of global competition today greatly accelerated the growth in international sourcing which allowed firms to utilize worldwide resources more effectively by enabling them to decouple regional economies from their countries of origin (Fawcett and Scully, 1998).

Monczka and Trent (2003) point to the increasing amounts and levels of international purchasing in their study of 162 mainly large companies worldwide.

Fawcett and Scully (1998) define international sourcing as "materials and component purchases from suppliers located outside the national borders". Throughout this study, international sourcing and international supplier selection are used interchangeably. Presence of factors such as complicated documentation requirements, trade regulations, quotas, customs duties, currency exchange rates, cultural differences, unique ethical standards in addition to complex distribution channels (Min and Galle, 1991) make it a more complex decision process compared to domestic sourcing. Eventually, many buyers unfamiliar with these factors often hesitate to internationalize their sourcing processes. 
A number of studies in the literature cite major benefits of the internationalization in supplier selection as reducing unit prices, gaining better access to product and process technology (Monczka and Trent, 2003), gaining access to new markets (Neureiter and Nunnenkamp, 2010), building long term ties (Servais et al., 2007), improving supplier production capability; intertwining business culture and practices; improving communication infrastructure (Ruamsook, 2009), enriching the managerial perspective (Mol, 2005), maximizing financial benefits (Grewal, 2008) among many others.

\section{Hierarchical Analysis of Supplier Selection Criteria}

Internationalization of sourcing requires the selection of suppliers in the international arena while considering political, social, economic and environmental dimensions in related countries. Fluctuations in exchange rates, international trade regulations, political interventions, cultural differences, environmental regulations are some country specific factors that should be considered in addition to the criteria related to domestic sourcing.

In the literature, many studies exist on supplier selection; however, most of them are limited to domestic sourcing. Weber et al. (1991) classify all published papers and identify quality, cost and on-time delivery as the most important supplier selection criteria in evaluating supplier performance. Barbarosoglu and Yazgac (1997) define performance assessment, business structure and quality system assessment as factors affecting the supplier selection. Cebi and Bayraktar (2003) emphasize logistics, technology, business and relationship as the related criteria. Suresh Babu and Kamana (2005) define quality, delivery, price, technology, financial stability, people, service, strategic business partnership in addition to safety and environmental concern as the significant factors. Chan and Kumar (2008) analyze the global supplier development problem and consider cost, quality, service performance, supplier profile and risk factor as important decision variables.

This paper attempts to construct a more comprehensive criteria hierarchy by extending the literature with global and contemporary aspects like international trade, supplier's environmental concern and country's globalization. In developing the main criteria, sub criteria and their hierarchy, primary and secondary sources are utilized. Additionally, interviews are conducted with the Turkish and Australian company decision makers in order to define significant and relevant criteria.

The hierarchy developed is presented in Figure 1. Level 1 represents the overall goal, Level 2 the major criteria and Level 3 the sub criteria. For the purpose of selecting the final supplier(s), the hierarchy can be extended with Level 4 which would include alternative suppliers. The goal is to select the best supplier in the international arena. Major criteria are defined as financial terms, supplier's profile, supplier's safety and environmental concern, supplier's quality management, delivery and global factors (Aytekin, 2009). These criteria will be discussed below along with the related sub criteria. 


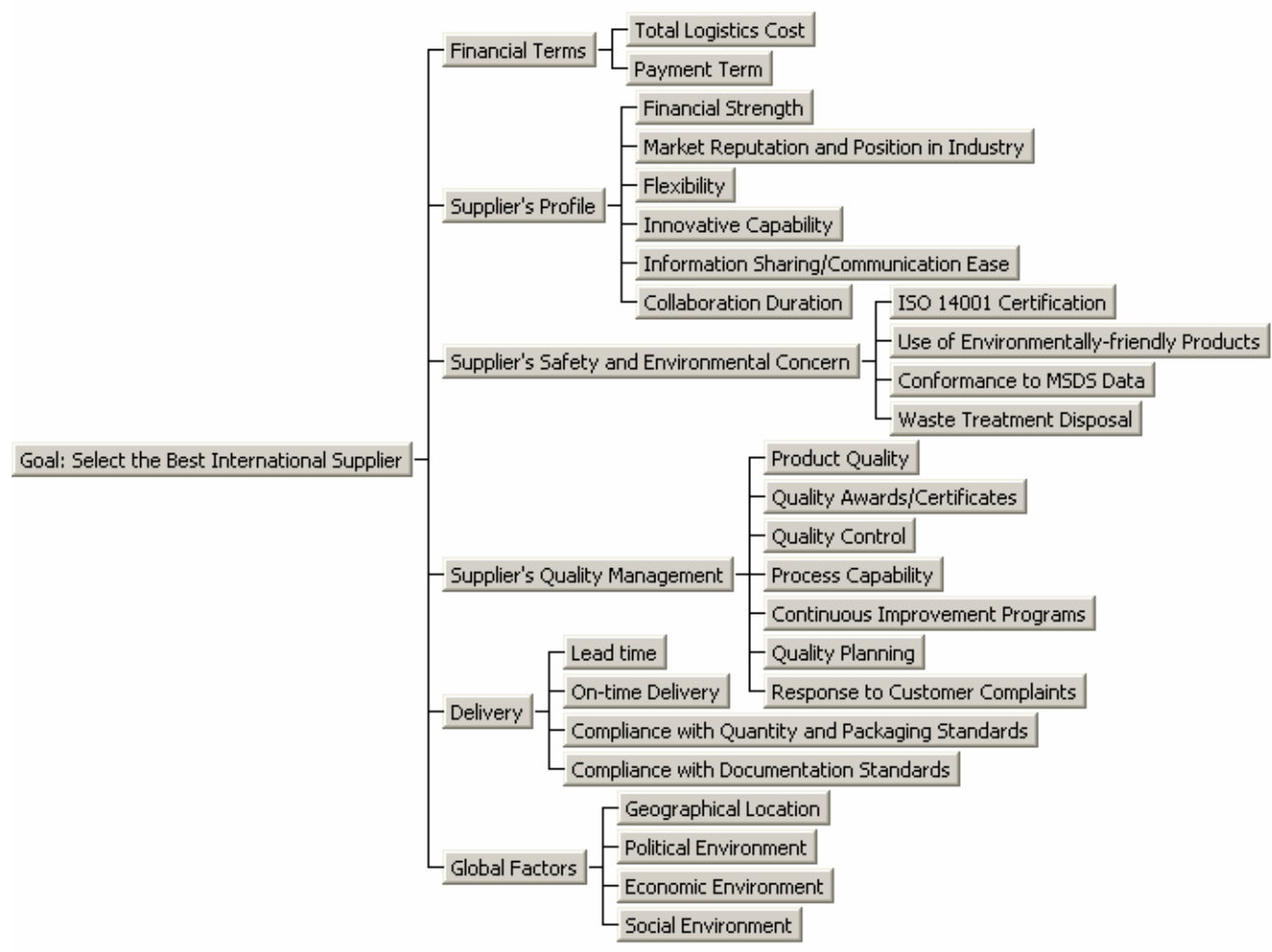

Figure 1. Hierarchy of International Supplier Selection Criteria

- Financial terms: is a critical criterion which directly affects the cost and profit levels. It is subdivided as

$>$ Total logistics cost and payment terms.

Before the decision makers decide on a specific supplier, they particularly consider the overall cost of receiving the product and the length of time interval that they can make the payment. Total logistics cost criterion involves purchase price, import duties, freight cost and ordering cost as defined in Ghodyspour and Brien's study (2001). International trade regulations, level of tariffs, presence of free trade agreements are some of the country specific factors that would affect the final cost.

- Supplier's profile criterion can be measured in terms of the following sub criteria:
> Supplier's financial strength,

$>$ market reputation and position in industry,

$>$ flexibility,

> innovative capability,

>information sharing and collaboration duration.

Suresh Babu and Kamana (2005) state that the supplier should have adequate funds to complete the project given and should be financially stable for at least 3-5 years. They also point to the advantages of supplier flexibility.

Flexibility would facilitate the adaptation to changing demands and needs. Chan et al. (2008) emphasizes that the supplier's innovative capability is of primary concern in 
international supplier selection. Innovation is regarded as the driving force behind increasing productivity and competitive power. Information sharing and collaboration duration would facilitate communication and, thus, transactions between buyer and supplier.

- Supplier's safety and environmental concern is incorporated in the model due to the increasing legal as well as public pressure on protection of environment and pollution. More companies link the particular supply chain management strategy with their supplier's environmental performance. Literature search and discussions with sourcing and production managers resulted in defining sub criteria as

> ISO 14001 certification,

$>$ use of environmentally-friendly products,

$>$ conformance to Materials Safety and Documentation Sheet (MSDS) data and waste treatment-disposal.

ISO 14001 specifies the requirements of an environmental management system for small to large organizations. If management anticipates new environmental issues, integrates environmental concerns throughout the manufacturing process and extends these ideas to inter-organizational linkages along the supply chain, environmental supply chain management will be successful (New and Westbrook, 2004, pg. 231). Conformance to MSDS, which requires controls for handling and storing of especially dangerous and poisonous materials, is also a critical issue for management.

- Supplier's quality management is a core issue since final product quality affects not only the relationship between the supplier and the buyer but the whole supply chain. This factor also constitutes one of the most important reasons for international sourcing. It is measured by
$>$ product quality,

$>$ quality awards/certificates,

$>$ quality control,

$>$ process capability,

$>$ continuous improvement programs,

quality planning and response to customer complaints.

Quality is an integral concept that is related to all the steps in the value chain. It covers the design quality of the product, the final product's conformance to specifications and after sale services such as responding to customer complaints. Therefore, these factors are taken into account as sub criteria.

The awards/certificates such as ISO 9001, HACCP received by the supplier at the national or international level are regarded as indications of quality standards.

The role of supplier's quality planning is important since the presence of policies could prevent various kinds of quality problems. Compliance with company specifications, prototype pre-production controls, traceability of shipped products, performance of quality improvement activities, follow-up of quality costs and the availability of a quality control database are the main indicators of the supplier's success in quality planning (Barbarosoglu and Yazgac, 1997).

Process capability is significant since it assists in investigating the supplier's capability to produce the quality products (Chan et al., 2008). The output of an incontrol process is compared to the specification limits using capability indices and the process's ability to create a product within specification limits is measured effectively. 
Continuous improvement programs like Kaizen and Six Sigma are tools for improving standardized activities and productivity. They are vital considering today's fast changing customer requirements along with high level of competition.

- Delivery is another critical factor in the international supplier selection model. Advances in on-line information systems ease international operations in custom brokers and freight forwarders and the lead time required for purchasing process decreases. Min (1994) emphasizes that the buyer should assess the reliability of the supplier's commitment for on-time delivery. Moreover, the firm must comply with packaging standards, predetermined order quantity and document management.

- Global factors are embedded in the model due to the selection of an increasing number of suppliers from foreign countries. Subcriteria considered are

$>$ geographical location,

>economic,

$>$ political and social environments in the supplier's country.

Geographical location of the supplier's country and the transportation route require careful analysis in order to eliminate the risk of disruption in the supply chain. Sourcing from suppliers of different locations also diversify certain risks of being in a single country such as strikes etc. The economic environment of the supplier's country is also significant since concepts like currency exchange rate, local price control, inflation rate, level of tariffs are directly related with it.

The political environment and the attitude towards business policies in the supplier's country may affect the long-term relationship between supplier and the buyer (Chan et al., 2008). For instance, during the Beijing Olympic Games in 2008, in an effort to reduce pollution and traffic congestion before, during and after the Games, Chinese government implemented a variety of measures to restrict and close down heavy pollution industries. These measures had a detrimental effect on international trade issues like disrupted cargo transportation and delayed deliveries. Additionally, politically more stable governments should be preferred since changing foreign policies may create major problems in maintaining relations with the supplier. In terms of the social environment, it would generally be advantageous for the buyer to consider attributes like cultural and ethical similarity.

\section{The Analytic Hierarchy Process}

AHP is a subjective decision making tool developed by Saaty (1977) that evaluates and weighs a number of criteria and sub criteria which affect the final decision. Unlike the subjective and priori weight assignments in a number of multi-attribute decision models, AHP calculates criteria weights systematically throughout the process itself which reduces subjectivity significantly. Using the same hierarchy and the criteria, one might end up with different criteria weights depending on the strategies or preferences of the decision makers (Saaty, 1990).

In an AHP model, a hierarchy is developed where the highest level is the overall goal followed by criteria and sub-criteria respectively, down the hierarchy. The criteria are compared and evaluated by the decision maker by constructing pair-wise comparison matrices for each hierarchy level. The decision maker answers the question of 'How important is factor A compared to factor B in reaching the final goal?' The responses are evaluated using a scale of 1 (equally important) to 9 (extremely important) as suggested by Miller (1956). The comparisons are reciprocal. If factor $A$ compared to factor $\mathrm{B}$ is rated 9 then $\mathrm{B}$ compared to $\mathrm{A}$ is rated $1 / 9$ (extremely less important). After comparing all possible pairs, mathematical operations are applied to the comparison 
matrix to obtain the relative priorities (weights) for each factor. Various matrices are prepared to evaluate the criteria at each level of the hierarchy. Matrices that show the pair-wise comparisons of the decision maker are checked for inconsistency to validate the responses of the decision maker (Saaty, 1990).

By employing this approach, not only are the rankings of criteria defined by a decision maker compared relatively, but also the importance given to those weights by two different companies in different countries can be examined. Hence, by creating a common AHP hierarchy that can be applied by decision makers in different countries, international sourcing strategies of organizations can be compared easily and systematically.

\section{Application of AHP to a Turkish and an Australian Company}

The AHP Model is applied to two chemical companies one operating in Turkey and the other in Australia. Application to two distinct companies from different countries would both test the differentiation power of the model and also highlight some country specific as well as company specific approaches to supplier selection problem. For this study, the major objective is to develop and apply the proposed multicriteria hierarchy and to interpret the criteria priority weights. For this reason, data about alternative suppliers and their evaluation as well as the final selection are not included in this case analysis.

The Australian company is a leading manufacturer of private label cosmetics, toiletries and theurapeutic goods located in Tullamarine, Victoria. It specializes in formulating and producing high quality products for leading retailers and major local and international brands. The Turkish chemical company is a worldwide supplier of innovative specialty chemicals and nutritional ingredients. The company, located in Izmit, delivers natural source raw materials and ingredients for nutrition and healthcare markets, cosmetics, detergents and cleaner industries. Chemical industry plays a key role in both countries' foreign trade; moreover, there is an upward trend on the import of chemicals in both countries.

The countries chosen depict some similarities economically such as level of imports and trade deficit. Some major differences exist politically such as difference in their geo-strategic position and culturally (social and business cultures).

Selecting companies from two distant countries reduce the impacts of regional proximity. Sector differences are also minimized by choosing companies from the same sector. As a result, differences in the results might be attributed more to country and company specific factors.

Data are acquired after a number of company visits and face to face interviews with each company's Sourcing Division manager and Supply Chain Manager. The managers are asked to make pair wise comparisons for each level in the hierarchy. Based on this data, criteria weights are obtained using Expert Choice Software.

Results will be discussed at three levels. First, main criteria and then the sub criteria will be evaluated with respect to the goal. Finally, related sub-criteria will be evaluated with respect to each criterion.

The two companies demonstrate some major differences in terms of their emphasis on each supplier selection criterion (Figure 2). 


Supplier's Quality Management
Delivery
Financial Terms
Supplier's Safety and Environmental Concern
Global Factors
Supplier's Profile
Inconsistency $=0,02$

Delivery
Financial Terms
Supplier's Profile
Global Factors
Supplier's Safety and Environmental Concern
Supplier's Quality Management
Inconsistency = 0,06

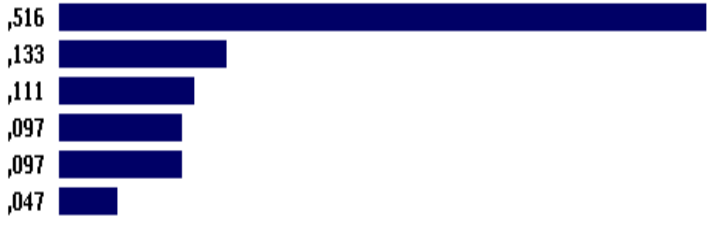

Australian

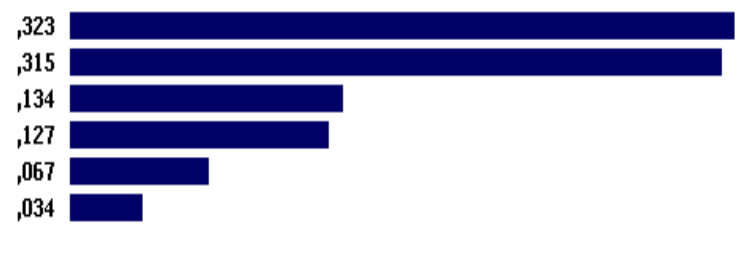

Turkish

Figure 2. Major Criteria Ranking for the Companies

For the Australian company, supplier's quality management is the major factor for the international supplier selection with 51.6 percent. This high value might be a reflection of tight quality control mechanism in the country. Supplier's delivery, which directly affects the just-in-time production strategy and the customer relations of the buyer, is ranked the second, with 13.3 percent. Financial terms criterion is rated almost as important as delivery. Similarly, supplier's safety and environmental concerns and the global factors are rated equally and there is no significant difference in the weights of these four criteria. This might indicate that the recent developments in the global arena are considered in international sourcing decisions. The supplier's profile constitutes the lowest percentage among them implying that the buyer does not care much about the supplier profile as long as requirements are met.

On the other hand, there is no single leading criterion for the Turkish company. Delivery and financial terms are assigned higher priority weights than quality which surprisingly constitutes the smallest percentage. The supplier's profile is found to be the third important criteria. This might be due to the difference in the trust level of companies for their suppliers. This is consistent with the fact that the level of risk is higher and trust is lower in Turkish business environment.

The weight of global factors is found to be slightly higher than that of Australian company. However, a weight of 12.7 percent might indicate that the global environment in the supplier's countries is still not much concerned with international sourcing decision. Additionally, supplier's safety and environmental concern is rated even much lower which shows that although the Turkish company considers global factors more than its Australian counterpart, it still does not place as much emphasis on protection of environment as its counterpart.

As a next step, the analysis is made at subcriteria level for the two companies. 
9 IBIMA Business Review

\begin{tabular}{|c|c|c|c|}
\hline Product Quality & 0,224 & Lead time & 0,136 \\
\hline Quality Control & 0,097 & On-time Delivery & 0,136 \\
\hline Response to Customer Complaints & 0,081 & Payment Term & 0,132 \\
\hline On-time Delivery & 0,058 & Compliance with Quantity and Packaging Standards & 0,106 \\
\hline Total Logistics Cost & 0,048 & Compliance with Documentation Standards & 0,062 \\
\hline Lead time & 0,046 & Flexibility & 0,056 \\
\hline Process Capability & 0,043 & Economic Environment & 0,053 \\
\hline Conformance to M5DS Data & 0,042 & Geographical Location & 0,048 \\
\hline Economic: Environment & 0,042 & Information Sharing/Communication Ease & 0,034 \\
\hline Quality Planning & 0,041 & Conformance to MSDS Data & 0,028 \\
\hline Pollitical Environment & 0,04 & Collaboration Duration & 0,021 \\
\hline Compliance with Documentation Standards & 0,033 & Pollitical Environment & 0,021 \\
\hline Continuous Improvement Programs & 0,031 & Innovative Capability & 0,02 \\
\hline Use of Environmentally-friendly Products & 0,024 & Totat Logistics Cost & 0,019 \\
\hline Collaboration Duration & 0,02 & Product Quality & 0,014 \\
\hline Quality Amards/Certficicates & 0,018 & Financial Strength & 0,013 \\
\hline Payment Term & 0,016 & Use of Environmentally-friendly Products & 0,013 \\
\hline Information Sharing/Communication Ease & 0,016 & Quality Control & 0,011 \\
\hline I50 14001 Certification & 0,015 & Process Capability & 0,011 \\
\hline Geographical Location & 0,012 & Quality Planning & 0,011 \\
\hline Waste Treatmenti|jisposal & 0,01 & Response to Customer Complaints & 0,011 \\
\hline Innovative Capability & 0,009 | & Social Environment & 0,011 \\
\hline Compliance with Quantity and Packaging Standards & 0,008 | & Continuous Improvement Programs & 0,009 \\
\hline Social Environment & 0,008 | & Market Reputation and Position in Industry & 0,008 \\
\hline Flexibility & 0,007 | & I50 14001 Certification & 0,007 \\
\hline Market Reputation and Position in Industry & 0,006 | & Waste Treatment|Disposal & 0,004 I \\
\hline Financial 5trength & 0,004 I & Quality Awards/Certificates & 0,002 \\
\hline Australian & & Turkish & \\
\hline
\end{tabular}

Figure 3. Sub-criteria Ranking for the Companies

Figure 3 shows that product quality, quality control and response to customer complaints are the most important factors among 27 sub-criteria for the Australian company that emphasizes especially the importance of product quality. Furthermore, the highest ranked ten sub-criteria belong to various major criteria except supplier's profile. The most important sub-criteria regarding profile is observed to be collaboration duration, followed by information sharing. Considering the global factors, social environment is ranked quite lower than economic and political environments and it accounts for the lowest percentage along with flexibility, market reputation as well as financial strength.
On the other hand, the Turkish company's ranking shows that delivery is the greatest determinant in international supplier selection. Unlike its counterpart, the Turkish company pays great attention to flexibility which reflects the general business environment in Turkey. Among the highest ranked ten sub-criteria, there doesn't exist any sub-criteria belonging to supplier's quality management. Additionally, although financial terms is ranked higher than supplier's profile and global factors, the number of sub-criteria of these two criteria in top ten is higher than that of financial terms. Unlike past research results in the literature, total logistics cost and product quality are ranked fourteenth and fifteenth respectively (see Figure 12). 
The environment related sub criteria ISO 14001 Certification and Waste treatment/disposal are rated almost the lowest; however, conformance to MSDS Data which is a significant part of supplier's safety concern is ranked among top ten.
Finally, companies' evaluation of sub-criteria with respect to relevant criteria is discussed. The sub-criteria under financial terms are ranked differently by the two companies (Figure 4).
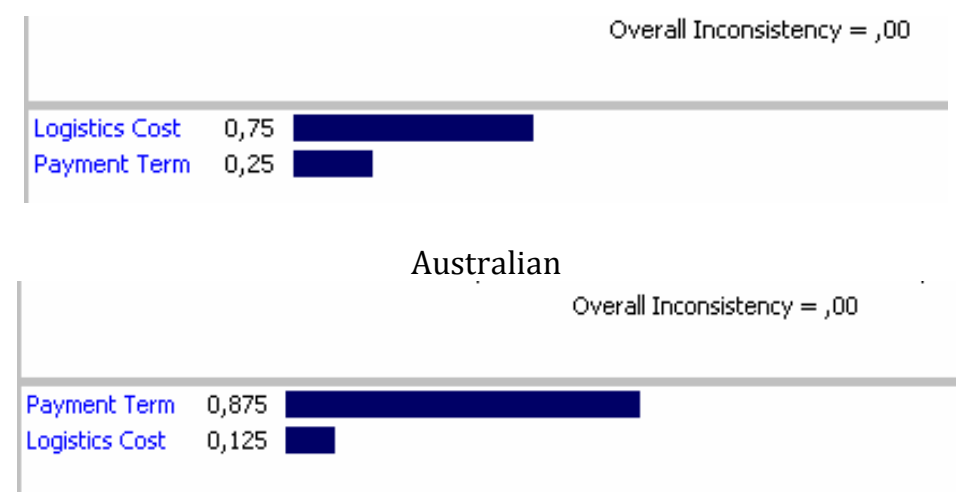

Turkish

Figure 4. Financial Terms Sub-criteria Ranking for the Companies

For the Australian company cost is three times as important as payment term whereas Turkish company evaluates payment term seven times as important. This indicates that the Turkish company does not want to tie up its capital and wants to select the supplier that offers it the longest time interval to make the payment or else cash flow is strictly important for him.
Results show that there is no significant difference between the two companies' view regarding sub-criteria under delivery, supplier's quality management and supplier's safety and environmental concern which matches with the expectations.

$$
\begin{aligned}
& \text { Economic Environment } \\
& \text { Political Environment } \\
& \text { Geographical Location } \\
& \text { Social Environment } \\
& \text { Inconsistency = } 0,01 \\
& \text { Economic Environment } \\
& \text { Geographical Location } \\
& \text { Political Environment } \\
& \text { Social Environment } \\
& \text { Inconsistency }=0,04
\end{aligned}
$$

413

389

082

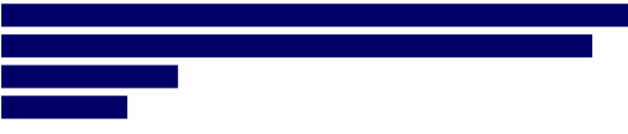

Australian

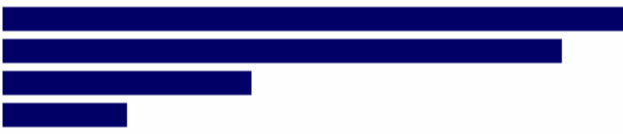

Turkish

Figure 5. Global Factors Sub-criteria Ranking for the Companies 
Figure 5 depicts that despite its remoteness from other countries, the Australian company does not consider geographical location of the supplier's country as much as the Turkish company. This might be due to tensions and conflicts between the neighbor countries of Turkey and the possibility of supply chain disruption especially in transportation of the products. In this respect, the mode and route of transportation creates a significant difference in decision maker's preference regarding location. Since the mode of transportation for the Australian company does not necessitate ground transportation as much as the Turkish one, it might not have considered location as much as its counterpart.

Interestingly, the Australian company considers economic and political environment more than geographical location (Figure 5). The weights given to the political environment by the two companies is surprising since Turkish company was expected to rate higher due to the less public sensitivity observed in Australia towards the political developments in other countries. However, the results show that the weight of Turkish company is almost half of the latter. In addition, like Turkish company, social environment in the supplier's country is found to be the least significant factor among other constituents of global factors.

The emphasis given to economic environment of the supplier's country by the two companies is quite similar which may result from the similarities in the economic as well as trade indicators of two countries such as exchange currency rates, tariff rates, import values, GDP ratios.

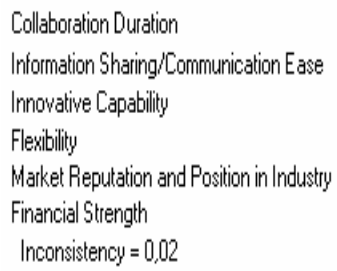

Flexibility
Information Sharing/Conmunication Ease
Collaboration Duration
Innovative Capability
Financial Strength
Market Reputation and Position in Industry
Inconsistency = 0,11

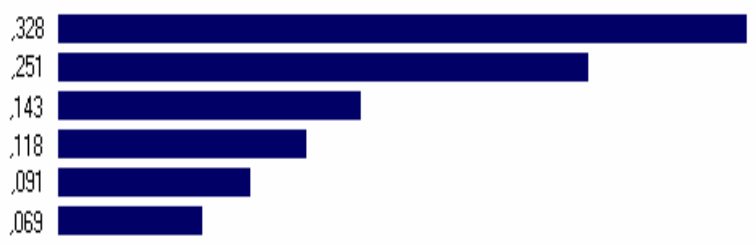

Australian

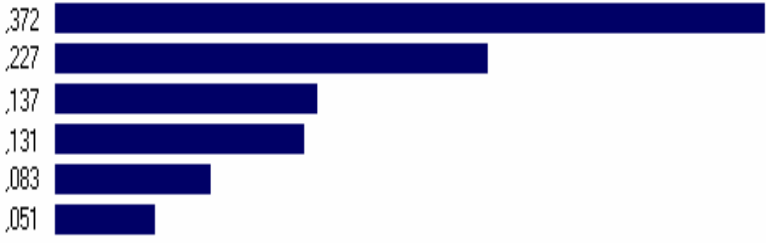

Turkish

Figure 6. Supplier's Profile Sub-criteria Ranking for the Companies

Figure 6 shows that for the Australian company, collaboration duration is the utmost important factor related with supplier's profile. This may imply that in case of supplier selection in a multiple-sourcing environment, the company cannot disregard the existing suppliers if they have been cooperating for a long time and there is a mutual gain and satisfactory relationship between the supplier and the company. On the other hand, for the 
Turkish company, supplier's response to changes in demand and order frequency is an utmost critical factor. It is also worth to note that neither company takes into account market reputation and financial strength as much as the other factors.

Two companies are analyzed to note for company based and country based similarities and differences. Although not included in this application, it can easily be taken a step further to evaluate and rank various suppliers. After determining criteria weights for each company, alternative suppliers are evaluated by company managers using pair wise comparisons and supplier weights are calculated similarly for each supplier on each criterion. The final weight of each supplier is calculated by multiplying the weight of each criterion with the supplier's weight on that criterion and summing up the terms for all criteria. Suppliers will be ranked in a decreasing order of weights.

\section{Extending the Approach to Incorporate Order Splitting}

AHP model systematically weighs and evaluates the priorities of a company in supplier selection decision. By multiplying the weight of each criterion and supplier's rating, the overall weight of each supplier is determined. In case of single sourcing, that would suffice to rank the suppliers. For the case of multiple sourcing, order splitting can be achieved by integrating a quantitative model such as linear programming (LP) to the AHP approach. This study will only propose the basics of such a model both for the sake of completeness and to show that a hybrid model can easily be formed to propose an optimal solution. The LP model presented below selects the best suppliers and allocates the orders among them optimally. The constraints state that a supplier cannot exceed its capacity (1), total order quantities must equal the demand (2), suppliers' aggregate capacity must be above demand (3), logistics cost cannot exceed the budget (4), number of suppliers have a limit (5), each order will exceed the minimum limit (6). The objective is to maximize the "total purchasing value" (TPV). Purchasing value for each supplier is calculated through the AHP process, by multiplying the weight of each criterion with the supplier weight on that criterion and then summing all related terms. Subsequently, the purchasing values are used as coefficients of the objective function in LP to allocate order quantities to the suppliers. Hence, not only does the hybrid model give indications about how the two countries approach the international sourcing problem but also aids the decision maker in selecting the external suppliers that best match his expectations.

Optimal Order Splitting Model

Max $T P V=\sum_{i=1}^{n} w_{i} x_{i}$

s.t.

$x_{i} \leq C_{i} y_{i} \quad i=1, \ldots . n$

$\sum_{i} x_{i}=D$

$\sum_{i=1}^{n} C_{i} \geq D$

$\sum_{i=1}^{n} c_{i} x_{i} \leq B$

$n_{\min } \leq \sum_{i} y_{i} \leq n_{\max }$

$x_{i} \geq Q_{i \min } y_{i} \quad i=1, \ldots . n$

where,

$x_{i}=$ Order quantity for the ith supplier

$w_{i}=$ AHP-calculated weights for the ith supplier

$c_{i}=$ Unit logistics cost of the ith supplier

$C_{i}=$ Capacity of the ith supplier

$D=$ Demand for the period 
$B=$ Total budget allocated for the given period

$n=$ Number of suppliers

$Q_{i \min }=$ Min order quantity of the ith supplier

$y_{i}=1$ if ith supplier is selected; 0 otherwise

\section{Conclusion}

The objective of the paper is to discuss the relevant and contemporary decision criteria that can be involved in international supplier selection, propose an approach that could aid decision makers when making decisions about supplier selection and order splitting. The paper especially contributes by identifying and compiling the important criteria along with introducing criteria like supplier's safety and environmental concern, political environment, social environment into the selection problem. Applying the AHP approach to an Australian and a Turkish company is another interesting and original aspect of this study. The results indicate some structural differences in criteria prioritizations and decision making habits of the two companies. Although the findings cannot be generalized at country level due to the small sample size, this might pave the way for further analyses that will be conducted at country level. Comparative studies might aid not only in supplier selection but also in designing supply chains and supplier strategies.

\section{References}

Aytekin, A. (2009). International Supplier Selection and Order Allocation Decision: A Comparison of a Turkish and an Australian Company, Unpublished Master Thesis, Bogazici University, Turkey.

Barbarosoglu, G. \& Yazgac, T. (1997). “An Application of the Analytic Hierarchy Process to the Supplier Selection Problem," Production and Inventory Management Journal, 38, 14-21.
Cebi, F. \& Bayraktar, D. (2003). “An Integrated Approach for Supplier Selection," Logistics Information Management, 16, 395-400.

Chan, F. T. S., Kumar, N., Tiwari, M. K., Lau, H. C. W. \& Choy, K. L. (2008). "Global Supplier Selection: a Fuzzy-AHP Approach," International Journal of Production Research, 46, 3825-3857

Fawcett, S. E. \& Scully, J. I. (1998). "Worldwide Sourcing: Facilitating Continued Success," Production and Inventory Management Journal, 39, 1-10.

Ghodsypour, S. H. \& O’Brien, C. (2001). “The Total Cost of Logistics in Supplier Selection, under Conditions of Multiple Sourcing, Multiple Criteria and Capacity Constraints," International Journal of Production Economics, 73, 15-27.

Miller, G. A. (1956). "The Magical Number Seven, Plus or Minus Two: Some Limits on Our Capacity for Processing Information," Psychological Review, 63, 81-97.

Min, H. (1994). "International Supplier Selection: a Multi-attribute Utility Approach," International Journal of Physical Distribution and Logistics Management, 24, 24-33.

Mol, M., Tulder, R. \& Beije, P. (2005). "Antecedents and Performance Consequences of International Sourcing," International Business Review, 14(5)., 599-617.

Monczka, R. M. \& Trent, R. J. (2003). "Understanding Integrated Global Sourcing," International Journal of Physical Distribution and Logistics Management, 33, 607-29.

Nassimbeni, G. (2003). "Local Manufacturing Systems and Global Economy: Are They Compatible? The Case of the Italian Eyewear District," Journal of Operations Management, 21, 151-171.

Neureiter, M. \& Nunnenkamp, P. (2010). Modes of International Sourcing and the Competitiveness of Firms: An Analysis of 
European Survey Data, Kiel Institute for the World Economy, Kiel Working Paper No. 1558

New, S. J. \& Westbrook, R. (2004). Understanding Supply Chains: Concepts, Critiques and Futures, Oxford, New York: Oxford University Press.

Ruamsook, K., Russell, D. M. \& Thomchick, E. A. (2009). "Sourcing from Low-Cost Countries: Identifying Sourcing Issues and Prioritizing Impacts on Logistics Performance," The International Journal of Logistics Management, 20(1)., 79-96.

Saaty, T. L. (1990). "An Exposition of the AHP in Reply to the Paper: Remarks on the Analytic Hierarchy Process," Management Science, 36, 259-268.

Servais, P, Zucchella, A. \& Palamara, G. (2007). "International Entrepreneurship and Sourcing: International Value Chain of Small Firms," Journal of Euromarketing, 16(1,2)., 105-117.

Suresh Babu, T. \& Kamana, S. (2005). "An Analytical Hierarchy Process for Vendor Election Evaluation," South Asian Journal of Management, 12, 101-115.

Tracey, M. \& Tan, C. L. (2001). "Empirical Analysis of Supplier Selection and Involvement, Customer Satisfaction and Firm Performance," Supply Chain Management: An International Journal, 6, 174-188.

Weber, C. A., Current, J. R. \& Benton, W. C. (1991). "Vendor Selection Criteria and Methods," European Journal of Operational Research, 50, 2-18. 